Proc. Indian Acad. Sci. (Earth Planet. Sci.), Vol. 97, No. 2, December 1988, pp. 117-125.

(C) Printed in India.

\title{
Cosmic-ray production rates of neon isotopes in meteorite minerals
}

\author{
N BHANDARI \\ Physical Research Laboratory, Navrangpura, Ahmedabad 380009, India \\ MS received 24 July 1987; revised 6 September 1988
}

\begin{abstract}
The rates of production of ${ }^{21} \mathrm{Ne}$ and ${ }^{22} \mathrm{Ne}$ in spallation reactions, both due to solar as well as galactic cosmic rays, in some major meteoritic minerals, e.g. olivines, feldspars and pyroxenes, are calculated using their energy spectra and excitation functions. The production profiles of ${ }^{21} \mathrm{Ne}$ and ${ }^{22} \mathrm{Ne}$ due to galactic cosmic rays, and the ${ }^{22} \mathrm{Ne} /{ }^{21} \mathrm{Ne}$ ratio depend upon the size of the meteoroid. The ${ }^{22} \mathrm{Ne} /{ }^{21} \mathrm{Ne}$ ratio is very sensitive to the abundance of sodium and consequently its depth profile is distinctly different in feldspars, the ratio increasing with depth rather than decreasing as in pyroxenes and olivines. In the near-surface regions, up to a depth of $2 \mathrm{~cm}$, production due to solar flare protons dominates, giving rise to a steep gradient in isotopic production as well as in the ${ }^{22} \mathrm{Ne} /{ }^{2 i} \mathrm{Ne}$ ratio. Composite production profiles are given and compared with measurements in some meteorites.
\end{abstract}

Keywords. Meteorites; solar flares; galactic cosmic rays; neon isotopes.

\section{Introduction}

The concentration of ${ }^{21} \mathrm{Ne}$ in stony meteorites provides a reliable method of determining their exposure ages and the ratio ${ }^{22} \mathrm{Ne} /{ }^{21} \mathrm{Ne}$ is useful in understanding the exposure history of the meteoroid and estimating the atmospheric ablation and shielding depth. Furthermore the three isotopes of neon $(20,21$ and 22) provide an accurate method of correcting for any primordial component and identifying grains irradiated by solar flare particles during precompaction stage of the meteoroid. Measurements in mineral separates are sometimes more useful than those in the bulk meteorite because they provide a comparatively clearer picture of the irradiation history of the meteorite. We have therefore calculated the rates of production of ${ }^{21} \mathrm{Ne}$ and ${ }^{22} \mathrm{Ne}$ due to galactic (GCR) and solar (SCR) particles in some common silicate minerals which are abundant in chondrites.

\section{Methodology}

The isotope production rates due to galactic cosmic rays depend on target element abundances, excitation functions and energy spectra of primary and secondary nucleons which, in turn, depend upon the size of the meteoroid and shielding depth. Here we follow the model of Bhandari and Potdar (1982) for calculating the flux of nucleons as a function of energy at various depths within a meteoroid of a given size. The GCR flux in the interplanetary space of $1.7 \mathrm{P} / \mathrm{cm}^{2}$. sec. $4 \pi$ ster. $(>1 \mathrm{BeV})$ is used here following Reedy and Arnold (1972). This represents a long-term (106 $-10^{7}$ years) average flux at $1 \mathrm{~A} . \mathrm{U}$. near the ecliptic. The energy spectra of nucleons within the 
meteorite are determined from the spectral shape parameter $\alpha$, based on the experimental work of Bhattacharya et al (1980) and Potdar et al (1986) who determined this parameter for spherical meteoroids of radii $6,9,15,25,50$ and $>400 \mathrm{~cm}$. Proton and neutron cross-sections for the production of neon isotopes for different target elements at some energies have been measured (Reedy and Arnold 1972 and references therein; Walton 1974; Walton et al 1976; Tobailem and Lassus St Genies 1977; Reedy et al 1979; Tobailem 1981; Baros and Regnier 1984). Michel et al (1986) and Aylmer et al (1987) determined some excitation functions from simulated thick target irradiations to proton beams as well as from thin target experiments. The excitation functions used here are the same as those adopted by Bhandari and Potdar (1982). In the case of ${ }^{22} \mathrm{Ne}$, direct production from various elements as well as via decay of ${ }^{22} \mathrm{Na}$ has been taken into account. There is some uncertainty in the excitation functions because of the lack of measurements, particularly for neutron-induced reactions. In such cases excitation functions for neutron-induced reactions are taken to be the same as those for the analogous proton-induced reactions. This introduces some uncertainty in the production rates but is not serious since the ${ }^{21} \mathrm{Ne}$ and ${ }^{22} \mathrm{Ne} /{ }^{21} \mathrm{Ne}$ ratio profiles agree well with the measured values in San Juan Capistrano, St Severin and Keyes meteorites (Bhandari and Potdar 1982). The ${ }^{22} \mathrm{Ne} /{ }^{21} \mathrm{Ne}$ profiles also agree with the Berne data (Eberhardt et al 1966). However, there is some uncertainty in the estimation of exposure ages of these meteorites. In their work Bhandari and Potdar (1982) used the mean values of the exposure ages-11.2 Ma for St Severin and $19 \mathrm{Ma}$ for San Juan Capistrano and Keyes. New analysis (Graf et al 1986) indicates somewhat higher exposure ages. If this is true the production rates given here will have been overestimated by the same factor, although the ${ }^{22} \mathrm{Ne} /{ }^{21} \mathrm{Ne}$ ratio would be unaffected. The adopted abundances of $\mathrm{Mg}, \mathrm{Al}, \mathrm{Si}$ and $\mathrm{Na}$, which are the main target elements in silicate minerals, are given in table 1 (Allen and Mason 1973).

A similar procedure is used for calculating the production rates due to solar cosmic rays except that, because of the low energy of primary protons, it is not necessary to consider secondary nucleon production. There is some uncertainty in the estimates of long-term average solar flare proton fluxes. The values of flux $J_{s}\left(>10 \mathrm{MeV} / \mathrm{cm}^{2}\right.$, sec. $4 \pi$ ster) and rigidity $R_{0}(\mathrm{MV})$ have been determined from studies of lunar rocks (Bhandari et al 1975; Kohl et al 1978). We use here two sets of energy spectra defined by $\left(J_{s}, R_{0}\right)=$ (i) $(125,125)$ and (ii) $(100,100)$. The solar proton flux, however, depends upon the heliocentric distance, being high near the sun, at the meteoroid perihelion, and decreasing significantly with distance as the meteoroid moves towards its aphelion, where it spends most of its time. The average flux, integrated over the orbit, has been found to be as low as $(40,100)$ for the St Severin meteorite (Lal and Marti 1977; Bhandari and Potdar 1982).

Table 1. Adopted abundances $(\%)$ of main target elements in silicate minerals.

\begin{tabular}{lcccl}
\hline & $\mathrm{Mg}$ & $\mathrm{Al}$ & $\mathrm{Si}$ & $\mathrm{Na}$ \\
\hline Olivine & $23 \cdot 9$ & 0.01 & $17 \cdot 8$ & 0.02 \\
Feldspar & 0.04 & $11 \cdot 0$ & 30.5 & 7.0 \\
Orthopyroxene & $17 \cdot 7$ & 0.06 & 26.0 & 0.03 \\
Clinopyroxene & 10.1 & 0.3 & $25 \cdot 3$ & 0.43 \\
\hline
\end{tabular}




\section{Results and discussion}

The production profiles of ${ }^{21} \mathrm{Ne}$ due to GCR and the ${ }^{22} \mathrm{Ne} /{ }^{21} \mathrm{Ne}$ ratio in clinopyroxene, olivine, orthopyroxene and feldspar in meteorites of different radii, i.e. $9,15,25,50 \mathrm{~cm}$ and infinitely large $(>400 \mathrm{~cm})$, are shown in figure $1(\mathrm{a}$ and $\mathrm{b})$. It can be seen that the isotope production rate first increases with depth, with the development of nuclear cascade reaching a maximum around $10-20 \mathrm{~cm}$ depth, and then, in larger meteorites, decreasing with subsequent attenuation of nucleons. Typical GCR production rates of ${ }^{21} \mathrm{Ne}$ from different target elements, i.e. $\mathrm{Mg}, \mathrm{Al}$ and $\mathrm{Si}$, in a spherical meteoroid of $50 \mathrm{~cm}$ radius at a depth of $20 \mathrm{~cm}$ within the meteoroid are given in table 2 to show their relative importance. The ${ }^{22} \mathrm{Ne} /{ }^{21} \mathrm{Ne}$ ratios are given in table 3 .

Calculations show that the GCR production profiles of ${ }^{21} \mathrm{Ne}$ and ${ }^{22} \mathrm{Ne}$ in major target elements follow a similar trend with depth, resulting in a monotonously decreasing ${ }^{22} \mathrm{Ne} /{ }^{21} \mathrm{Ne}$ profile in olivines and pyroxenes. The ${ }^{22} \mathrm{Na}$ production from $\mathrm{Na}$, which is produced in $(n, 2 n)$ reaction, has a relatively flat profile compared to its production in other target elements. For this reason, in feldspars which contain large amounts of $\mathrm{Na}$, the $\left({ }^{22} \mathrm{Ne}+{ }^{22} \mathrm{Na}\right) /{ }^{21} \mathrm{Ne}$ ratio increases with depth. Starting around 1.6 near the surface, the ${ }^{22} \mathrm{Ne} /{ }^{21} \mathrm{Ne}$ ratio attains a value of 2.4 at a depth of $50 \mathrm{~cm}$ in large meteoroids, mainly owing to this reaction. The neon ratio in feldspars is thus, to a first approximation, sensitive to the pre-atmospheric size of the meteoroid. The isotopes ${ }^{21} \mathrm{Ne}$ and ${ }^{22} \mathrm{Ne}$ are also favourably produced in (n, alpha) reaction on ${ }^{24} \mathrm{Mg}$ and ${ }^{25} \mathrm{Mg}$ respectively. As ${ }^{24} \mathrm{Mg}$ isotopic abundance $(78.99 \%)$ is much higher than ${ }^{25} \mathrm{Mg}$ abundance $\left(10 \%\right.$ ) in olivines, where $\mathrm{Mg}$ content is high, the ${ }^{22} \mathrm{Ne} /{ }^{21} \mathrm{Ne}$ ratio remains low (between 1.2 and 0.98) for large meteoroids. The lowest production of ${ }^{21} \mathrm{Ne}$ occurs in feldspars and the highest in olivines because of the abundance of $\mathrm{Mg}$ which is the main target. The ${ }^{22} \mathrm{Ne} /{ }^{21} \mathrm{Ne}$ ratio in olivines and pyroxenes decreases from 1.2 or 1.3 near the surface to a value around 1 at a depth of $50 \mathrm{~cm}$ in large meteoroids.

Table 2. GCR production rate of ${ }^{21} \mathrm{Ne}\left(10^{-8} \mathrm{cc} \mathrm{STP} \mathrm{g.} \mathrm{Ma)}\right.$ in various minerals for different target elements in a $50 \mathrm{~cm}$ radius meteoroid at a depth of $20 \mathrm{~cm}$.

\begin{tabular}{lcccc}
\hline & $\mathrm{Mg}$ & $\mathrm{Al}$ & $\mathrm{Si}$ & Total \\
\hline Olivine & 0.468 & 0.00 & 0.078 & 0.546 \\
Feldspar & 0.001 & 0.06 & 0.133 & 0.194 \\
Orthopyroxene & 0.347 & 0.001 & 0.144 & 0.462 \\
Clinopyroxene & 0.198 & 0.002 & 0.111 & 0.311 \\
\hline
\end{tabular}

Table 3. Spallation ${ }^{22} \mathrm{Ne} /{ }^{21} \mathrm{Ne}$ ratio in various target elements in a $50 \mathrm{~cm}$ radius meteoroid.

\begin{tabular}{llll}
\hline Shielding depth & $\mathrm{Mg}$ & $\mathrm{Al}$ & $\mathrm{Si}$ \\
\hline $3 \mathrm{~cm}$ & 1.032 & 1.25 & 1.32 \\
At centre & 0.96 & 1.33 & 1.36 \\
\hline
\end{tabular}




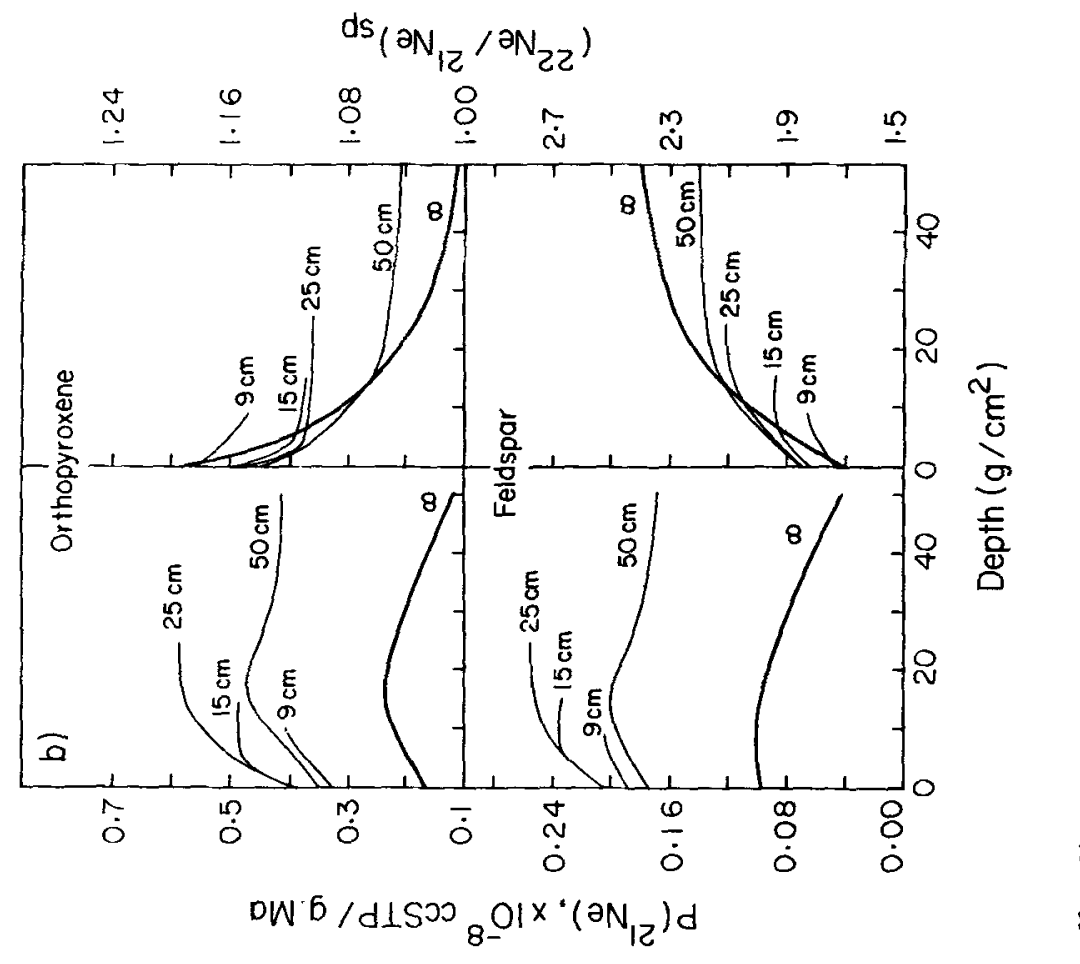

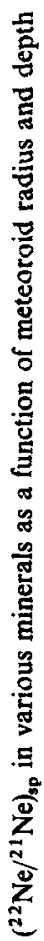

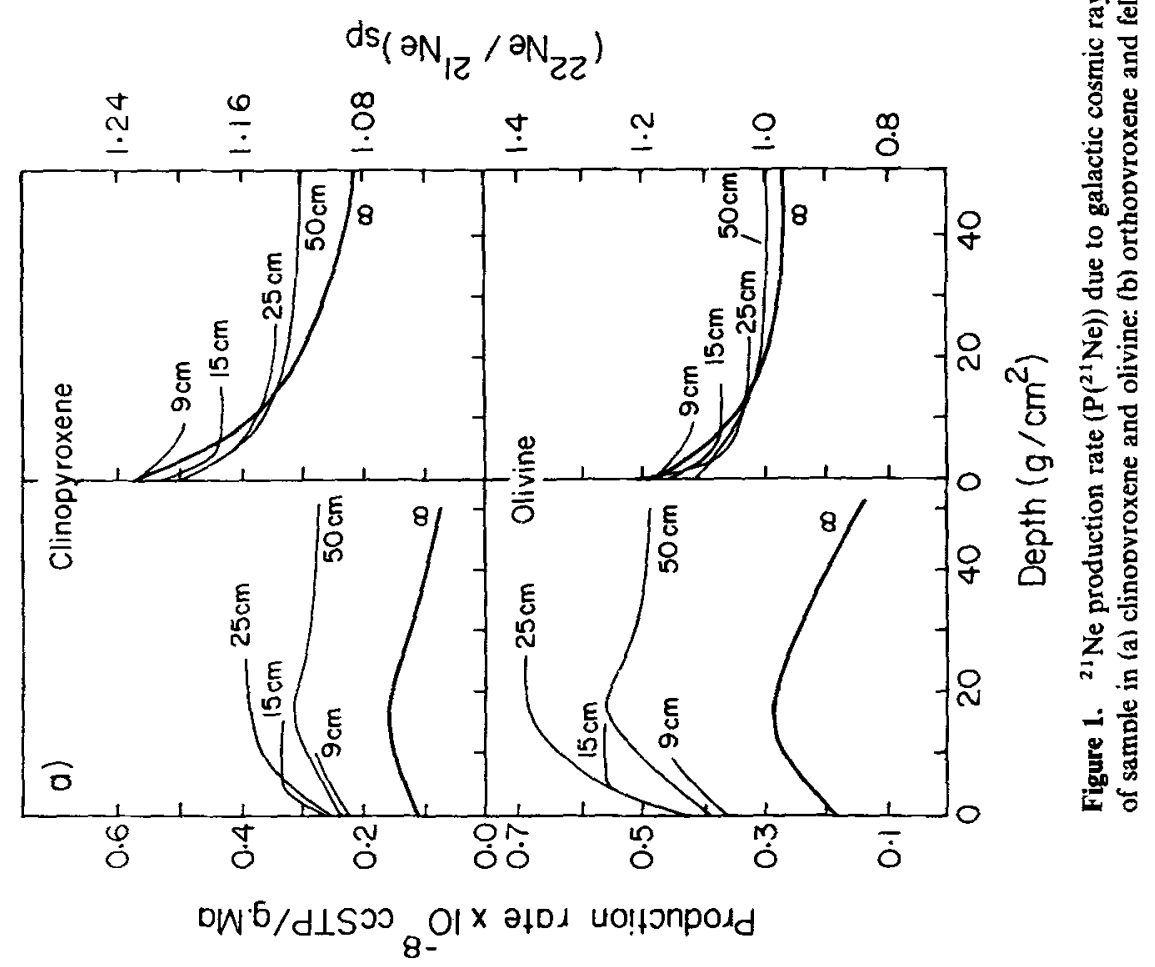


The solar production profiles in various minerals are shown in figure 2 for $\left(J_{s}, R_{0}\right)=(100,100)$ and $(125,125)$, after the GCR contribution has been added. The total production rates are given in tables 4 and 5 for some selected depths and sizes. In all cases, the ${ }^{22} \mathrm{Ne}$ production rate is higher than that of ${ }^{21} \mathrm{Ne}$ and the ${ }^{22} \mathrm{Ne} /{ }^{21} \mathrm{Ne}$ ratio monotonically decreases with depth (figure.2), approaching the pure GCR value at about $5 \mathrm{~cm}$. The high ratio in feldspars of $\sim 3$ is mainly due to ${ }^{23} \mathrm{Na}(\mathrm{p}, \mathrm{pn}){ }^{22} \mathrm{Na}$ reaction, which is very favourable.

The above calculations can be compared with the observed values in minerals separated from chondrites. Bochsler et al (1969) and Cressy and Bogard (1976) made measurements of neon isotopes in mineral separates from Bruderheim, Elenovka, etc. Their data show that the ${ }^{22} \mathrm{Ne} /{ }^{21} \mathrm{Ne}$ ratio is directly correlated with Si content and inversely with $\mathrm{Mg}$ content. In Bruderheim silicates, where $\mathrm{Mg} / \mathrm{Si}$ varies between 0.5 and $1 \cdot 2$, the ${ }^{22} \mathrm{Ne} /{ }^{21} \mathrm{Ne}$ ratio ranges between 1.09 and $1 \cdot 14$. Elenovka feldspars, ${ }^{22} \mathrm{Ne} /{ }^{21} \mathrm{Ne}=1 \cdot 25$ for pure $\mathrm{Si}(\mathrm{Mg} / \mathrm{Si}=0)$. The shielding depths within the meteoroids are however not known. We can obtain some rough estimates of shielding depths from the track density data. Bruderheim was a shower and the fragments, in general, had high ablation, 6-15 cm as estimated in a few cases by Bhandari et al (1980). Elenovka was also a multiple fall and the three fragments analysed had shielding depths between 3 and $9 \mathrm{~cm}$ (Bhandari et al 1980). These observed values can be compared with the calculated ratios given in figures 1 and 2 . The calculated ${ }^{22} \mathrm{Ne} /{ }^{21} \mathrm{Ne}$ ratio (at shielding depth of $3 \mathrm{~cm}$ ) in olivines and pyroxenes varies between 0.98 and

Table 4. GCR production rates of ${ }^{21} \mathrm{Ne}\left(10^{-8} \mathrm{cc} \mathrm{STP/g} \mathrm{Ma)} \mathrm{in} \mathrm{various} \mathrm{minerals} \mathrm{as} \mathrm{a}\right.$ function of depth and radius, $R$, of the meteoroid.

\begin{tabular}{|c|c|c|c|c|c|c|c|}
\hline \multirow[b]{2}{*}{ Mineral } & \multirow[b]{2}{*}{$R(\mathrm{~cm})$} & \multicolumn{6}{|c|}{ Depth (cm) } \\
\hline & & 10 & 20 & 30 & 40 & 100 & At centre \\
\hline \multirow[t]{5}{*}{ Olivine } & 9 & & & & & & 0.450 \\
\hline & 15 & 0.562 & & & & & 0.562 \\
\hline & 25 & 0.64 & 0.688 & & & & 0.688 \\
\hline & 50 & 0.509 & 0.546 & 0.513 & 0.497 & & 0.494 \\
\hline & $\infty$ & 0.27 & 0.276 & 0.237 & 0195 & 0.079 & \\
\hline \multirow[t]{5}{*}{ Feldspar } & 9 & & & & & & 0.211 \\
\hline & 15 & 0.237 & & & & & 0.237 \\
\hline & 25 & 0.247 & 0.253 & & & & 0.253 \\
\hline & 50 & 0.195 & 0.194 & 0.179 & 0.172 & & 0.170 \\
\hline & $\infty$ & $0-1$ & 0.092 & 0.076 & 0.06 & 0.018 & \\
\hline \multirow[t]{5}{*}{ Clinopx } & 9 & & & & & & 0.278 \\
\hline & 15 & 0.336 & & & & & 0.336 \\
\hline & 25 & $0 \cdot 372$ & 0.392 & & & & 0.395 \\
\hline & 50 & 0.296 & 0.310 & $0-290$ & 0.280 & & 0.278 \\
\hline & $\infty$ & 0.155 & 0.158 & 0.131 & $0 \cdot 108$ & 004 & \\
\hline \multirow[t]{5}{*}{ Orthopx } & 9 & & & & & & 0.396 \\
\hline & 15 & 0.486 & & & & & 0.486 \\
\hline & 25 & 0.546 & 0.583 & & & & 0.583 \\
\hline & 50 & 0.434 & 0.461 & 0.432 & 0.418 & & 0.415 \\
\hline & $\infty$ & 0.215 & 0.232 & 0.197 & 0.113 & 0063 & \\
\hline
\end{tabular}



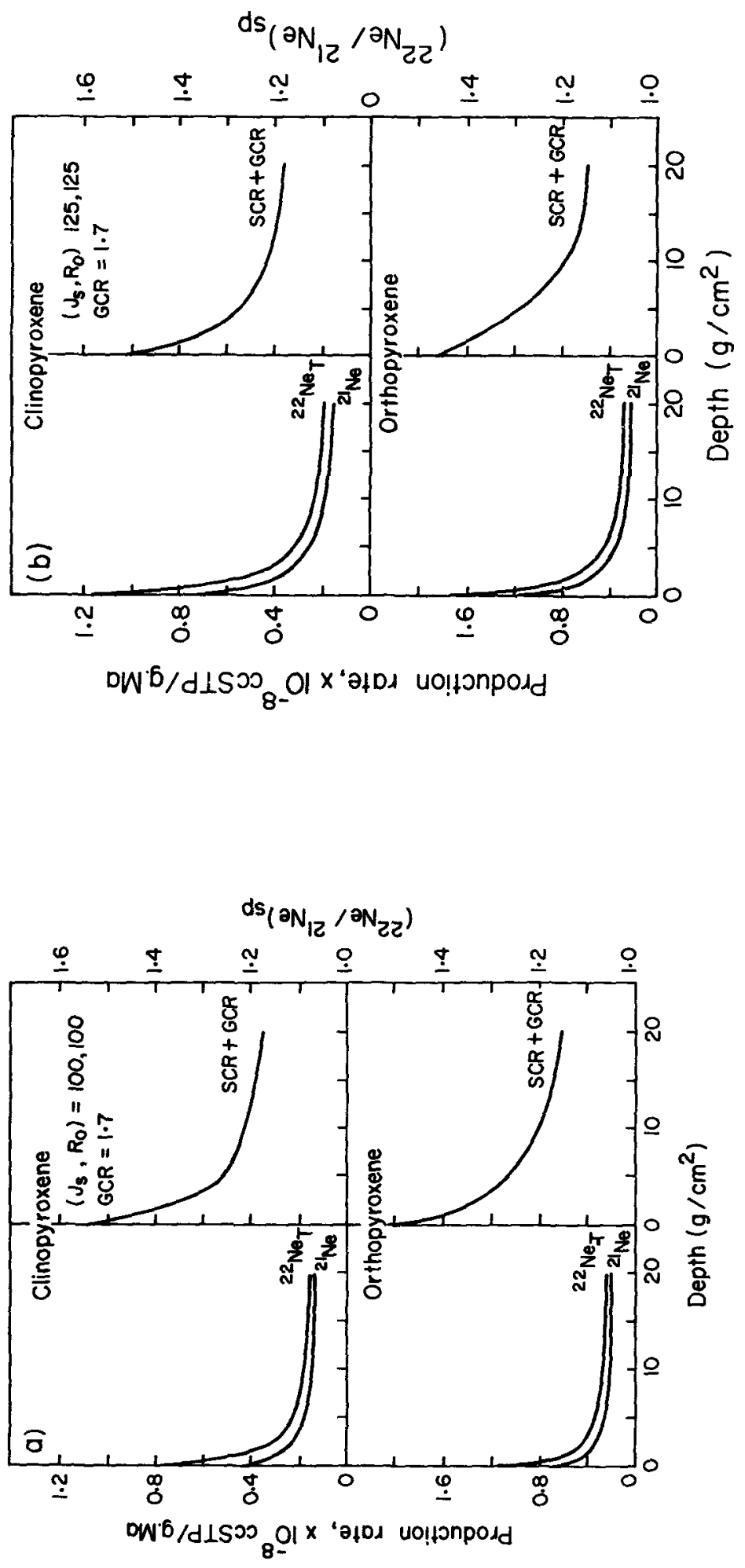


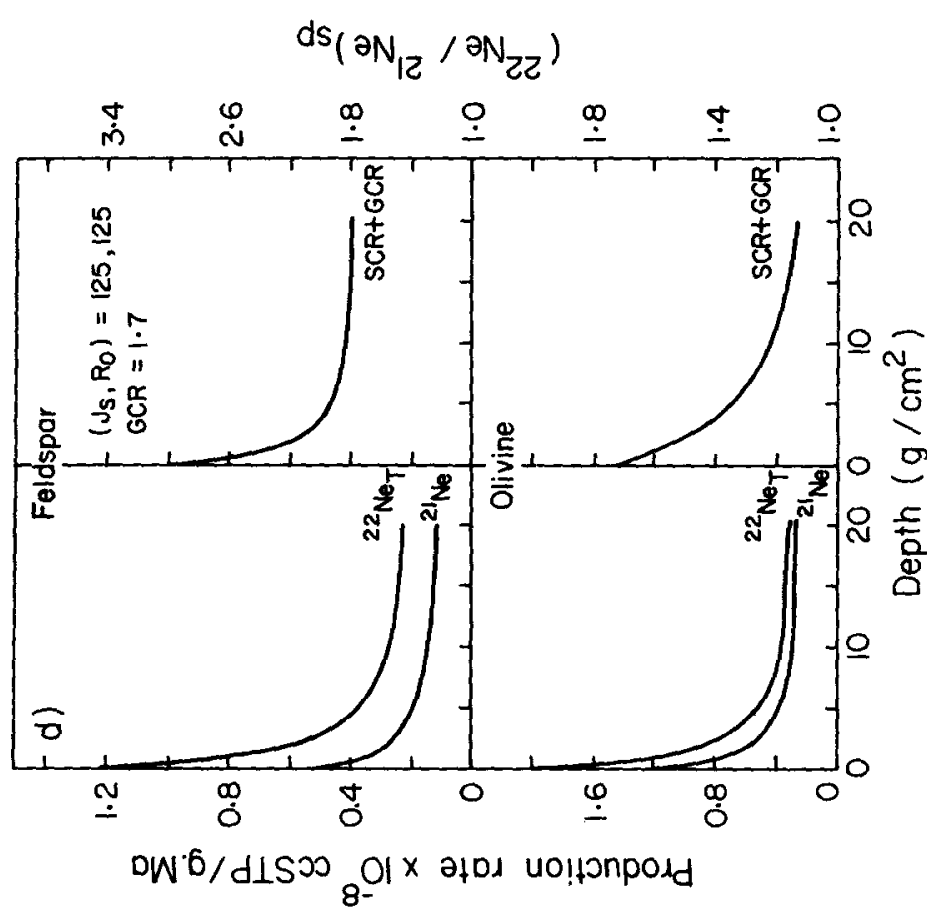

或

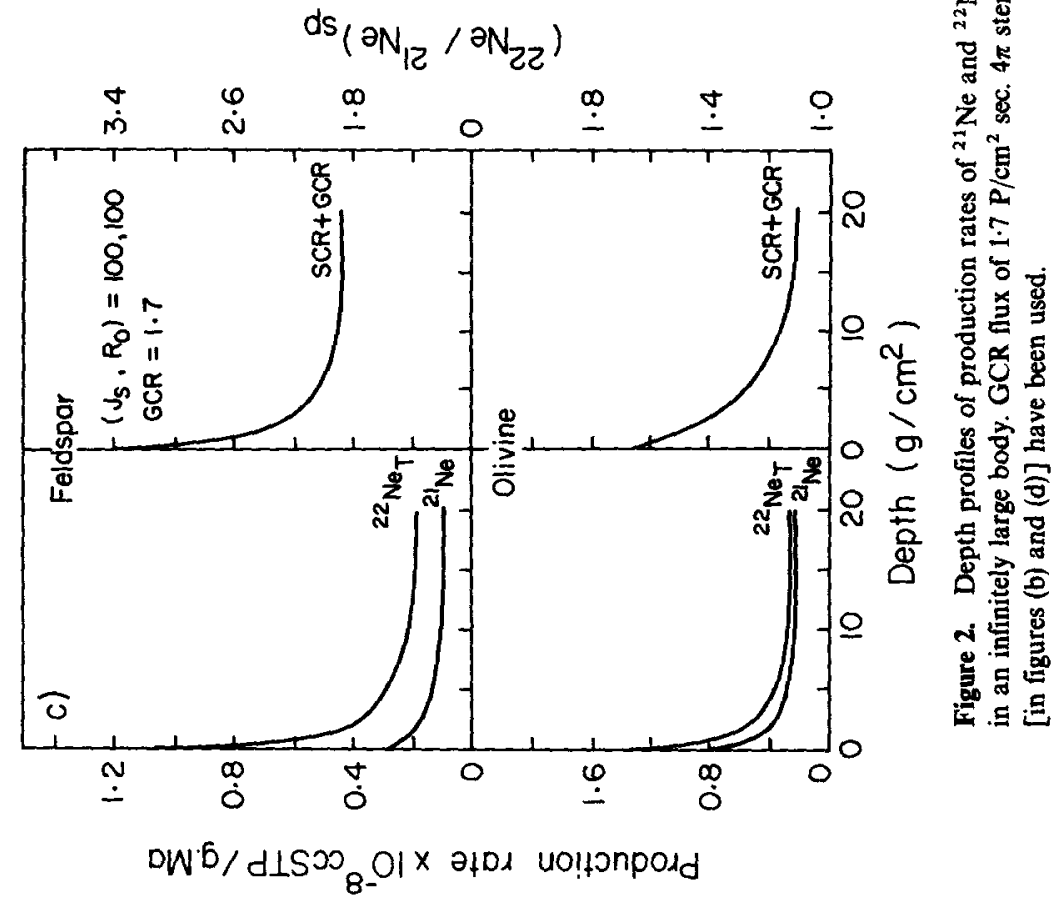


Table 5. GCR production ratio ${ }^{22} \mathrm{Ne} /{ }^{21} \mathrm{Ne}$ in various minerals as a function of depth and radius, $R$, of the meteoroid.

\begin{tabular}{|c|c|c|c|c|c|c|c|}
\hline \multirow[b]{2}{*}{ Mineral } & \multirow[b]{2}{*}{$R(\mathrm{~cm})$} & \multicolumn{6}{|c|}{ Depth $(\mathrm{cm})$} \\
\hline & & 10 & 20 & 30 & 40 & 100 & At centre \\
\hline \multirow[t]{5}{*}{ Olivine } & 9 & & & & & & $1 \cdot 122$ \\
\hline & 15 & $1 \cdot 077$ & & & & & 1.077 \\
\hline & 25 & 1.042 & 1.026 & & & & 1.026 \\
\hline & 50 & 1.041 & 1.013 & $1 \cdot 007$ & 1.003 & & 1.001 \\
\hline & $\infty$ & 1.055 & 0.995 & 0.976 & 0.974 & 0.879 & \\
\hline \multirow[t]{5}{*}{ Feldspar } & 9 & & & & & & 1.832 \\
\hline & 15 & 1.947 & & & & & 1.947 \\
\hline & 25 & $2 \cdot 052$ & $2 \cdot 109$ & & & & $2 \cdot 109$ \\
\hline & 50 & 2.058 & $2 \cdot 158$ & $2 \cdot 181$ & $2 \cdot 198$ & & $2 \cdot 205$ \\
\hline & $\infty$ & 2.02 & $2 \cdot 21$ & $2 \cdot 312$ & $2 \cdot 35$ & $2 \cdot 925$ & \\
\hline \multirow[t]{5}{*}{ Clinopx } & 9 & & & & & & $1 \cdot 199$ \\
\hline & 15 & $1 \cdot 173$ & & & & & $1 \cdot 173$ \\
\hline & 25 & $1 \cdot 152$ & $1 \cdot 14$ & & & & $1 \cdot 141$ \\
\hline & 50 & $1 \cdot 151$ & $1 \cdot 32$ & $1 \cdot 128$ & $1 \cdot 126$ & & $1 \cdot 125$ \\
\hline & $\infty$ & $1 \cdot 154$ & $1 \cdot 124$ & $1 \cdot 107$ & 1.096 & 1.032 & \\
\hline \multirow[t]{5}{*}{ Orthopx } & 9 & & & & & & $1 \cdot 149$ \\
\hline & 15 & $1 \cdot 111$ & & & & & $1 \cdot 111$ \\
\hline & 25 & 1.082 & 1.068 & & & & 1.065 \\
\hline & 50 & 1.081 & 1.056 & $1 \cdot 051$ & 1.047 & & 1.046 \\
\hline & $\infty$ & 1.087 & 1.046 & $1 \cdot 024$ & 1.014 & 0.932 & \\
\hline
\end{tabular}

$1 \cdot 18$, which is consistent with the values in Bruderheim quoted above. The calculated ${ }^{22} \mathrm{Ne} /{ }^{21} \mathrm{Ne}$ ratio of 1.15 also compares favourably with the observed value of $1 \cdot 138$ in Elenovka pyroxenes. In the case of feldspars, corrected for their sodium abundance of $4 \%$, we estimate ${ }^{22} \mathrm{Ne} /{ }^{21} \mathrm{Ne}$ to be 1.5 , which is higher than the observed value of 1.25. The reason for this discrepancy may lie in the excitation function for production in sodium. Bochsler et al (1969) gave values of $1.07 \pm 0.03$ and $1.35 \pm 0.15$ for ${ }^{22} \mathrm{Ne} /{ }^{21} \mathrm{Ne}$ for spallation in $\mathrm{Mg}$ and $\mathrm{Si}$ respectively, which also compare well with the values of $0.96-1.032$ and $1.32-1.36$ given in table 3 for a $50 \mathrm{~cm}$ meteoroid. Thus our calculations seem to give ${ }^{22} \mathrm{Ne} /{ }^{21} \mathrm{Ne}$ values in silicate minerals in reasonable agreement with the available observations. The ${ }^{21} \mathrm{Ne}$ production rates and ${ }^{22} \mathrm{Ne} /{ }^{21} \mathrm{Ne}$ profiles are also in agreement with the observations, as shown by the detailed analysis made by Bhandari and Potdar (1982) and Sarafin et al (1985) in San Juan Capistrano, Keyes and other meteorites. These profiles can be further refined as better crosssections and depth profiles in meteorites become available.

\section{Acknowledgements}

The author is grateful to $\mathrm{Mr} \mathrm{K} \mathrm{M}$ Suthar for assistance in computations and to Drs P N Shukla, M N Rao and Mr J T Padia for useful comments. 


\section{References}

Allen R O Jr and Mason B 1973 Minor and trace elements in some meteoritic minerals; Geochim. Cosmochim. Acta 37 1435-1456

Aylmer D, Begemann F, Cloth P, Dragovitsch P, Englert P, Filges D, Herpers U, Herzog G F, Jermaikan A, Klein J, Kruse T H, Michel R, Moniot R K, Middleton R, Peiffer F, Signer P, Stück R, Theis S, Tuniz C, Vadja S, Weber H and Wieler R 1987 Monte Carlo modelling and comparison with experiment of the nuclide production in thick stony targets isotropically irradiated with $600 \mathrm{MeV}$ protons; Report ISSN 0366-0885 Kernfirschungsanlage Julich Gmbh

Baros F and Regnier S 1984 Measurement of cross-sections for ${ }^{22} \mathrm{Na},{ }^{20-22} \mathrm{Ne}$ and ${ }^{36-42} \mathrm{Ar}$ in the spallation of $\mathrm{Mg}, \mathrm{Al}, \mathrm{Si}, \mathrm{Ca}$ and $\mathrm{Fe}$. Production ratios of some cosmogenic nuclides in meteorites; J. Phys. 45 855-861

Bhandari N and Potdar M B 1982 Cosmogenic ${ }^{21} \mathrm{Ne}$ and ${ }^{22} \mathrm{Ne}$ depth profiles in chondrites; Earth Planet. Sci. Lett. 58 116-128

Bhandari N, Bhattacharya S K and Padia J T 1975 The surface radioactivity of lunar rocks: implications to solar activity in the past; Proc. 6th Lunar Sci. Conf. Geochim. Cosmochim. Acta Suppl. 7 1913-1925

Bhandari N, Lal D, Rajan R S, Arnold J R, Marti K and Moore C B 1980 Atmospheric ablation in meteorites: a study based on cosmic ray tracks and neon isotopes: Nucl. Tracks 4 213-262

Bhattacharya S K, Imamura M, Sinha N and Bhandari N 1980 Depth and size dependence of ${ }^{53} \mathrm{Mn}$ activity in chondrites; Earth Planet. Sci. Lett. 51 45-57

Bochsler H, Eberhardt P, Geiss J and Grögler N 1969 Rare gas measurements in separate mineral phases of the Otis and Elenovka chondrites. In Meteorite research (ed) P M Millman (Dordrecht: D Rejdel) pp. 857-874

Cressy P J and Bogard D D 1976 On the calculation of cosmic ray exposure ages of stone meteorites: Geochim. Cosmochim. Acta. 40 749-762

Eberhardt P, Eugster O, Geiss J and Marti K 1966 Rare gas measurements in 30 meteorites; Z. Naturforsch. 21 414-440

Graf Th, Signer P and Wieler R 1986 Production rates of light noble gases, ${ }^{10} \mathrm{Be}$ and ${ }^{26} \mathrm{Al}$ in chondrites; Meteoritics 21 376-377

Kohl C P, Murrel M T, Russ G P III and Arnold J R 1978 Evidence for the constancy of the solar cosmic ray flux over the past ten million years: ${ }^{53} \mathrm{Mn}$ and ${ }^{26} \mathrm{Al}$ measurements; Proc. 9th Lunar Sci. Conf, Geochim. Cosmochim. Acta Suppl. $102299-2310$

Lal D and Marti K 1977 On the flux of low energy particles in the solar system: The record in St Severin meteorite; Nucl. Track Detect. 1 127-130

Michel R, Dragovitsch P, Englert P, Peiffer F, Stuck R, Theis S, Begemann F, Weder H, Signer P, Wieler R, Filges D and Cloth P 1986 On the depth dependence of spallation reactions in a spherical thick diorite target homogeneously irradiated by $600 \mathrm{MeV}$ protons: Nucl. Instr. Meth. Phys. Res. B16 61-82

Potdar M B, Bhandari N and Suthar K M 1986 Radionuclide depth profiles in Dhajala chondrite; Proc. Indian Acad. Sci. (Earth Planet. Sci.) 95 169-182

Reedy R C, Herzog G F and Jessberger E K 1979 The reaction Mg $(n, \alpha)$ Ne at 14.1 and 14.7 MeV: Crosssections and implications for meteorites; Earth Planet. Sci. Lett. 44 341-348

Reedy R C and Arnold J R 1972 Interaction of solar and galactic cosmic ray particles with the moon; $J$. Geophys. Res. 77 537-555

Sarafin R, Bourot-Denise M, Crozaz G, Herpers U, Pellas P, Schultz L and Weber H W 1985 Cosmic ray effects in the Antarctic meteorite Allan Hills 78084; Earth Planet. Sci. Lett. 73 171-182

Tobailem J 1981 Sections efficaces des reactions nucleaires induites par protons, deutons, particules alpha V-Silicium. Note CEA-N-1466 (5)

Tobailem J and Lassus St Genies C H 1977 Sections efficaces des reactions nucleaires induites par protons, deutons, particules alpha, IV-Aluminium, Note CEA-N-1466 (4)

Walton J R 1974 Production of He, Ne and Ar in lunar material by solar cosmic ray protons; $\mathrm{PhD}$ thesis, Rice University, USA

Walton J R, Heymann D, Yaniv A, Edgerley D and Rowe M W 1976 Cross-sections for He and Ne isotopes in natural $\mathrm{Mg}, \mathrm{Al}$ and $\mathrm{Si}, \mathrm{He}$ isotopes in $\mathrm{CaF}_{2}, \mathrm{Ar}$ isotopes in natural $\mathrm{Ca}$ and radionuclides in natural $\mathrm{Al}$, $\mathrm{Si}, \mathrm{Ti}, \mathrm{Cr}$ and stainless steel induced by 12 to $45 \mathrm{MeV}$ protons; J. Geophys. Res. 81 5689-5699 